\title{
Passive Transplacental Immunization: Influence on the Detection of Enteric Antigen in the Systemic Circulation
}

\author{
R. E. KLEINMAN, ${ }^{(15)}$ P. R. HARMATZ, L. A. JACOBSON, J. N. UDALL, K. J. BLOCH, AND W. A. \\ WALKER \\ Gastrointestinal and Nutrition Unit of the Children's Service and Clinical Immunology and Allergy Unit of the \\ Medical Services, Massachusetts General Hospital and the Departments of Pediatrics and Medicine, Harvard Medical \\ School, Boston, Massachusetts, USA
}

\begin{abstract}
Summary
Female New Zealand white rabbits were immunized with bovine serum albumin (BSA). Litters which had never suckled, from immunized and nonimmunized rabbits, were tested at $4 \mathrm{~h}, 24 \mathrm{~h}$, and $48 \mathrm{~h}$ after birth. After obtaining an initial blood sample, all infant rabbits were gavaged with $100 \mathrm{mg}$ of BSA plus tracer amounts of $\left[{ }^{125} I\right]$-BSA. Infant rabbits born to immunized mothers had circulating antibody before feeding and pups from nonimmunized mothers had no detectable antibody to BSA. The fed animals were sacrificed at 3-4 h after gavage. Serum obtained from cardiac and portal blood was examined for protein bound radioactivity and for the presence of immunoreactive BSA (iBSA) by electroimmunodiffusion. All infant rabbits had radioactivity in their blood. Approximately $50 \%$ of the radioactivity in the serum of infant rabbits from nonimmunized does was protein bound and all of these animals had iBSA in portal or cardiac serum samples. Of the 33 infant rabbits from immunized does, only four had protein bound radioactivity in their serum. This radioactivity appeared to be associated with circulating immune complexes of $\left[{ }^{125} \mathrm{I}\right]-\mathrm{BSA}$ rabbit-anti-BSA antibodies. None of the 33 infant rabbits had iBSA detectable by electroimmunodiffusion.
\end{abstract}

\section{Abbreviations}

$\mathrm{ABC}_{33}$, antigen binding capacity at $33 \%$ of potential binding capacity

BSA, bovine serum albumin

iBSA, immunoreactive bovine serum albumin

PBS, phosphate buffered saline

Serum antibodies passively transferred across the placenta provide an important part of systemic and possibly of intestinal host defense of the newborn in several animal species including man $(3,6)$. In the present study, we sought to determine whether such passively acquired antibodies to enteric antigens limit the detection of these antigens in the circulation. The sera of infant rabbits, which had been fed with antigens for which they had the corresponding maternal antibodies, were also examined for the presence of circulating immune complexes.

\section{MATERIALS AND METHODS}

Animals. Adult New Zealand white does raised on Charles River Rabbit Chow (Country Foods, Syracuse, NY), a plant-based diet devoid of BSA, were immunized by subcutaneous injection of $30 \mathrm{mg}$ of BSA (Sigma Chemical Co., St. Louis, MO) emulsified in complete Freund's adjuvant and were boosted twice at 14-day intervals with BSA dissolved in phosphate-buffered $(0.01 \mathrm{M})$ saline, $\mathrm{pH} 7.4$ (PBS). One month after the final immunization, the rabbits were mated. The litters from these rabbits, together with infant rabbits from nonimmunized does, were separated from the does immediately after birth and placed in an incubator at $30^{\circ} \mathrm{C}$ and fasted until studied. Blood was obtained from immunized does by venipuncture 1 month before and at the time of delivery and serum was examined for antigen-binding activity (see below). Blood was also obtained by cardiac puncture from some passively immunized and nonimmunized infant rabbits from each litter; these sera were also examined for antigen-binding capacity.

Transport studies. Five times crystallized BSA (Sigma Chemical Co., St. Louis, MO) was radiolabeled with $\left[{ }^{125} \mathrm{I}\right]$ (New England Nuclear, Boston, MA) using the modified Bolton-Hunter technique (2). $\left[{ }^{125} \mathrm{I}\right]-\mathrm{BSA}$ was applied to a Sephadex G-25 gel filtration column; the peak radioactive fraction of the void volume, containing substances with a molecular weight greater than 5000 Daltons was mixed together with cold BSA dissolved in PBS to yield a specific activity of approximately $3 \times 10^{4} \mathrm{cpm} / \mathrm{mg} \mathrm{BSA}$. Twentythree rabbits were tested $4 \mathrm{~h}$ after birth. Groups of 20 infant animals were also studied $24 \mathrm{~h}$ and $48 \mathrm{~h}$ after birth. All infant animals were fasted until tested and none were allowed to suckle. One hundred $\mathrm{mg}$ of $\left[{ }^{125} \mathrm{I}\right]$-BSA solution $(1.0 \mathrm{ml})$ was administered by gavage to immunized and control infant rabbits. Three to four hours after gavage, animals were anesthetized lightly and bled from the heart (cardiac sera) and from the portal vein (portal sera) through a small laparotomy incision. In preliminary experiments on normal animals, peak levels of iBSA were achieved in portal and cardiac blood between 3-4 $\mathrm{h}$ after gavage.

Examination of serum for radioactivity, $i B S A$ and $\left[{ }^{125} I\right]-B S A-$ anti-BSA complexes. The radioactivity in 5-100 $\mu \mathrm{l}$ samples of serum was measured in a crystal scintillation spectrometer (Beckman Instruments, Inc., Fullerton, CA). Serum was delipidated by centrifugation at $13,000 \mathrm{rpm}$ for $30 \mathrm{~min}$ in a Beckman-21 centrifuge (Beckman Instruments). Protein-bound radioactivity was determined after precipitating plasma proteins with $10 \%$ trichloracetic acid. In some samples, protein-bound radioactivity was determined by measuring the radioactivity of the sample before and after dialysis in tubing with a molecular weight cutoff of 1000 Daltons (Spectrum Medical Industries, Los Angeles, CA). Samples were dialyzed against PBS for $24 \mathrm{~h}$ at $4^{\circ} \mathrm{C}$.

The concentration of circulating iBSA was determined in all samples of portal and cardiac blood obtained. Sera were examined by the electroimmunodiffusion method of Laurell (7). Rabbit antiBSA (Myles Laboratories, Elkhart, IN or Cappel Laboratories, Cochranville, PA) was mixed with $1 \%$ agarose and applied as a thin layer on glass slides. Samples were placed in a series of wells and were subjected to an electric field. Precipitin arcs, formed in the reaction between iBSA in the sample and anti-BSA antiserum in the gel, were measured and the amount of iBSA was determined by comparison with a standard curve prepared with solutions of known BSA content. The lower limit of sensitivity of this method was $1 \mu \mathrm{g}$ of iBSA per ml serum.

Serum samples were also applied to sucrose density gradients 
(15-40\% sucrose) and centrifuged at $27,000 \mathrm{rpm}$ for $14 \mathrm{~h}$ at $4^{\circ} \mathrm{C}$ in a Beckman L5-65 ultracentrifuge. Fractions were collected as previously described (12). The radioactivity in each fraction was measured before and after the addition of $100 \mu \mathrm{l}$ of either rabbit anti-BSA or goat anti-rabbit IgG antiserum added to $300 \mu \mathrm{l}$ of each fraction. The mixture was held at $37^{\circ} \mathrm{C}$ for $1 \mathrm{~h}$ and at $4^{\circ} \mathrm{C}$ for $18 \mathrm{~h}$. The resulting precipitate was washed once and its content of radioactivity was determined.

Measurement of antigen-binding activity. The antigen-binding activity of serum from actively (does) and passively (infant rabbits) immunized rabbits was determined by the method of Farr (8). The $\mathrm{ABC}_{33}$ at $0.25 \mu \mathrm{g} \mathrm{BSA}$ per $\mathrm{ml}$ was determined.

\section{RESULTS}

$A B C_{33}$ of maternal and infant sera. Sera obtained from the four immunized does during pregnancy and at delivery had an $\mathrm{ABC}_{33}$ ranging from $250-300 \mu \mathrm{g} / \mathrm{ml}$. Sera from the 33 infant rabbits of immunized does had an $\mathrm{ABC}_{33}$ ranging from $160-250 \mu \mathrm{g} / \mathrm{ml}$. No antigen-binding activity was detected in sera from nonimmunized animals.

Mucosal uptake of BSA. After the administration by gavage of a mixture of $\left[{ }^{125} \mathrm{I}\right]$-labeled and "cold" BSA, radioactivity appeared in the portal and cardiac blood of all 63 infant rabbits bled 3-4 h later (Table 1). In infant rabbits from nonimmunized does, approximately $50 \%$ of the radioactivity was precipitable with TCA. Except for four of 33 animals, there was virtually no trichloracetic acid-precipitable radioactivity in the serum of infant rabbits from immunized does. The concentration of immunoreactive BSA was determined by electroimmunodiffusion. Nonimmunized infant rabbits had a mean of $10.42 \pm 2.42 \mu \mathrm{g} / \mathrm{ml}$ of iBSA in serum from portal blood and $5.56 \pm 1.49 \mu \mathrm{g} / \mathrm{ml}$ of iBSA in serum from cardiac blood samples. No iBSA was detectable in either portal or cardiac sera of immunized infant rabbits.

On analysis by sucrose density gradient ultracentrifugation, serum from cardiac blood obtained from nonimmunized infant rabbits $4 \mathrm{~h}$ after gavage with BSA, showed a broad zone of radioactivity in the upper one-third of the gradient. Very little radioactivity was present in fractions constituting the lower twothirds of the gradient. Addition of anti-BSA antiserum to fractions constituting the upper one-third, precipitated approximately $60 \%$ of the radioactivity from fractions equivalent to numbers $20-25$ (Fig. 1). In separate experiments, these fractions were found to contain the peak of radioactivity after ultracentrifugation of $\left[{ }^{125} \mathrm{I}\right]$ -BSA used as a gradient marker.

On density gradient ultracentrifugation of sera obtained from immunized infant rabbits (including the four cited below) $4 \mathrm{~h}$ after gavage, a broad zone of radioactivity was again observed in the upper one-third of the gradients (Fig. 1). In addition, sera from four test animals showed peaks of radioactivity near the bottom of the gradient. Addition of anti-BSA antiserum to fractions from the upper one-third of the gradient did not precipitate any radioactivity; addition of anti-BSA precipitated approxi-

Table 1. Radioactivity and immunoreactive bovine serum albumin ( $i B S A)$ in sera of immunized and nonimmunized animals administered $\left[{ }^{125} I\right]-B S A$ and "cold" BSA by gavage

\begin{tabular}{|c|c|c|c|c|}
\hline & $n^{1}$ & Immunized & $n$ & Nonimmunized \\
\hline $\begin{array}{l}\mathrm{cpm} / \mathrm{ml} \text { (in serum from car- } \\
\text { diac or portal blood) }\end{array}$ & 33 & $10,870 \pm 340^{2}$ & 30 & $10,450 \pm 900$ \\
\hline $\begin{array}{l}\text { \% protein bound radioactiv- } \\
\text { ity (in serum from cardiac } \\
\text { or portal blood) }\end{array}$ & $\begin{array}{r}29 \\
4\end{array}$ & $\begin{array}{l}<1 \\
49 \pm 3.7\end{array}$ & 30 & $47 \pm 9.7$ \\
\hline $\begin{array}{l}\text { iBSA }(\mu \mathrm{g} / \mathrm{ml}) \text { (serum from } \\
\text { cardiac blood) }\end{array}$ & 33 & 0 & 30 & $5.56 \pm 1.49$ \\
\hline $\begin{array}{l}\text { iBSA }(\mu \mathrm{g} / \mathrm{ml})(\text { serum from } \\
\text { portal blood })\end{array}$ & 33 & 0 & 30 & $10.42 \pm 2.42$ \\
\hline
\end{tabular}

\footnotetext{
${ }^{1}$ Number of animals tested.

${ }^{2}$ Mean values \pm S.E. of all sera tested.
}

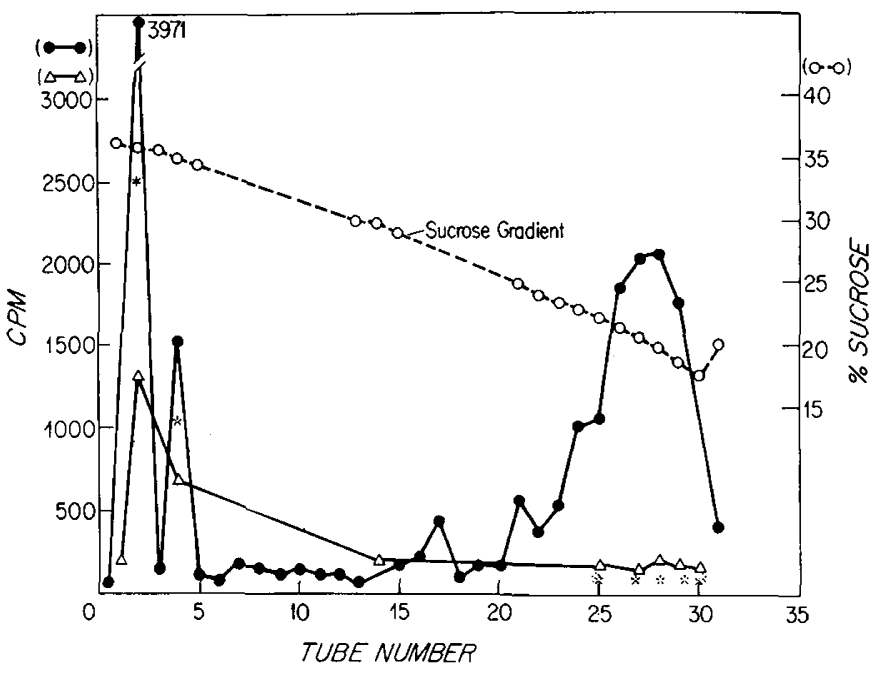

Fig. 1. Sucrose density gradient ultracentrifugation profile of cardiac serum from a passively immunized rabbit pup given $\left[{ }^{125} \mathrm{I}\right]$-bovine serum albumin solution by gavage. Radioactivity detected in individual fractions (- - - ) is shown, as is the radioactivity precipitated by anti-rabbit $\operatorname{IgG}(\Delta---\Delta)$ and rabbit anti-bovine serum albumin antiserum $\left({ }^{*}\right)$.

mately $60 \%$ of the radioactivity from the bottom fractions. Addition of anti-rabbit IgG anti-serum precipitated approximately $30 \%$ of the radioactivity from these fractions (Fig. 1).

\section{DISCUSSION}

In the rabbit, the active maternal transfer of immunoglobulin, mainly $\operatorname{IgG}$, from maternal to infant circulation occurs in utero via the yolk sac (4). The infant rabbit also receives maternal $\mathrm{IgG}$, IgM, and IgA from ingested colostrum, but like the human, there appears to be no active transport of these immunoglobulins from intestine into the systemic circulation (6). Antibodies of the latter two classes were not involved in the present study because infant rabbits were prevented from suckling. In this study we have shown that passive immunization of the newborn with antibody to BSA derived from the maternal circulation limits the appearance of detectable BSA in the systemic circulation.

Radioactivity appeared in the sera of all infant rabbits fed a mixture of BSA and $\left[{ }^{125} \mathrm{I}\right]-\mathrm{BSA}$. In nonimmunized control animals, this radioactivity was partially associated with trichloroacetic acid-precipitable material and was nondialyzable (through dialysis bags with 1000 molecular weight cutoff, data not shown). In part, the radioactivity sedimented on sucrose density gradients in the same zone as [ $\left.{ }^{125} \mathrm{I}\right]$-BSA and was partially precipitable by antiBSA antiserum. Immunoreactive BSA was detected by electroimmunodiffusion in both portal and cardiac blood obtained from nonimmunized infant rabbits. The large difference in iBSA concentration of portal and systemic blood of nonimmunized animals, suggests hepatic sequestration of this protein. The mechanism of the apparent hepatic sequestration is not known.

In serum from all but four of the 33 passively immunized infant rabbits the radioactivity, which also sedimented in a broad zone at the upper one-third of a sucrose density gradient, was dialyzable and not precipitable by trichloroacetic acid; hence it probably represents free iodine or small radioactive peptides. No iBSA could be detected by electroimmunodiffusion, either in cardiac or portal sera from all 33 animals. In four animals that were tested at $4 \mathrm{~h}$ after birth, there was a peak of radioactivity at the bottom of the density gradient in addition to that present at the top. On the basis of molecular size and precipitation by both anti-BSA antiserum and anti-rabbit IgG antiserum, the radioactive material at the bottom of the gradient most likely represents complexes of $\left.{ }^{125} \mathrm{I}\right]$-BSA and rabbit IgG anti-BSA antibodies. Aggregates of radiolabeled BSA may also be present to account for the lower $\%$ of radioactivity precipitated by anti-rabbit IgG antiserum. 
Alternatively, the difference in amounts of radioactivity precipitated by the two antisera may reflect differences in precipitability of the two antigen-antibody systems.

Several explanations for the failure to detect free iBSA in either cardiac or portal blood from the 33 passively immunized infant rabbits may be considered. Antibody may combine with antigen in the lamina propria and the resulting complexes may subsequently be transported via portal blood to the liver for clearance or via lymph to other systemic clearance sites. Degradation of labeled antigen at these sites, with subsequent release of $\left[{ }^{125} \mathrm{I}\right]$ alone or as small peptides might account for the equivalent amounts of total radioactivity in the blood of immunized and control animals (Table 1). The observations of other investigators provide support for these suggestions. Thus, Tolo, et al. (11) have shown significant retardation in the in vitro transfer of albumin across buccal mucosa from rabbits immunized with BSA compared to control animals. Thomas and Vaez-Zadeh (10) demonstrated in rats that the liver is capable of removing antigenantibody complexes thereby preventing the appearance of antigen in the circulation. A second possibility is that passively acquired antibody is disposed at the luminal surface of the intestine of the infant rabbit and forms complexes with fed antigen at this site. Complex formation would tend to immobilize antigen at the mucosal surface and render it susceptible to degradation by surface-associated enzymes (13). The subsequent uptake of $\left.{ }^{125} \mathrm{I}\right]$ or labeled small peptides might again account for the equivalent levels of radioactivity in the blood of passively immunized and control infant rabbits. A third possibility is that equivalent amounts of antigen are taken up from the lumen into the systemic circulation of passively immunized and control rabbits but that formation of immune complexes occurs rapidly in the former, followed by prompt clearance from the circulation, most likely by the liver. Degradation of complexes in Kupfer cells, with subsequent release of $\left[{ }^{125} \mathrm{I}\right]$ and small peptides may again be cited to account for the equivalent levels of total radioactivity in the blood (Table 1). Failure to detect circulating immune complexes in all but four infant rabbits may be attributed to the efficiency of the hepatic clearance of complexes. In the four rabbits with circulating immune complexes, hepatic clearance may be retarded, or delayed uptake of antigen from the gut may be responsible for the presence of complexes in the blood sample 3-4 h after feeding of antigen. Because the present study was not designed to determine the site of antigen-antibody interaction or the disposition of such complexes, we are unable to decide among the possibilities cited.

Immune complexes are, at least potentially, injurious to vascular and renal structures (5). Further, it might even be considered that complex formation in the lamina propria of the gut might lead to injury at this site. Normally, however, it would be expected that infant rabbits from actively immunized does would be supplied transplacentally and via suckling with systemic and enteric antibodies respectively and that the latter would reduce or completely prevent access of enteric antigens to IgG antibodies in mucosal and intravascular sites. The amount of single antigens ingested under normal conditions would also be expected to be less than the dose used in the present experiment, further reducing the likelihood that enteric antibodies would be overwhelmed and that large amounts of antigen would become available for combination with systemic IgG antibodies. What then might be the advantage of passively providing the neonate with such systemic antibodies? One possibility is that IgG antibodies provide a backup system for effectively removing (by complex formation and macrophage clearance) enteric antigens that have avoided mucosal exclusion mechanisms. This backup mechanism might be especially useful during the neonatal period when intestinal secretions are deficient in antibodies $(9,12)$ that contribute to immune exclusion of food antigen (1).

\section{REFERENCES AND NOTES}

1. Andre, C., Lambert, R., Bazin, H., and Heremans, J. F.: Interference of oral immunization with the intestinal absorption of heterologous albumin. Eur. J. Immunol., 4: 701 (1974).

2. Bolton, A. E. and Hunter, W. M.: The labelling of proteins to high specific radioactivities by conjugation to a ${ }^{125}$ I-containing acylating agent. Biochem. J., 133: 529 (1973).

3. Brambell, F. W. R.: The transmission of immunity from mother to young and the catabolism of immunoglobulins. Lancet, 2: 1087 (1966).

4. Brambell, F. W., Hemmings, W. A., Oakly, C. L., and Parker, R. R.: The relative transmission of the fractions of papain hydrolyzed homologous gamma globulin from the uterine cavity to the foetal circulation in the rabbit. Proc. Roy. Soc. (Biol.), 151: 478 (1960).

5. Cochrane, C. G. and Koffler, D.: Immune complex disease in experimental animals and man. Adv. Immunol., 16: 185 (1973).

6. Kraehenbuhi, J. P. and Campiche, M. A.: Early stages of intestinal absorption of specific antibodies in the newborn. An ultrastructural cytochemical and immunological study in the pig, rat, and rabbit. J. Cell Biol., 42: 345 (1969).

7. Laurell, C. B.: Quantitative estimation of proteins by electrophoresis in agarose gel containing antibodies. Anal. Biochem., 15: 45 (1966).

8. Minden, R. and Farr, R. S.: Ammonium sulphate method to measure antigen binding capacity. In: Handbook of Experimental Immunology, Ed.: D. M. Weiss, p. 13.1 (Oxford, Blackwell, 1978).

9. Selner, J. C., Merrill, D. A., and Claman, H. N.: Salivary immunoglobulins and albumin. Development during the newborn period. J. Pediatr., 72: 685 (1968).

10. Thomas, H. C. and Vaez-Zadeh, F.: A homeostatic mechanism for the removal of antigen from the systemic circulation. Immunology, 26: 375 (1974).

11. Tolo, K., Brandtzaeg, P., and Jonsen, J.: Mucosal penetration of antigen in the presence or absence of serum derived antibody. An in vitro study of rabbit oral and intestinal mucosa. Immunology, 33: 733 (1977).

12. Walker, W. A.: The nature and role of mucosal surface immunity against infection in the newborn. In: Immunological Aspects of Infection in the Fetus and Newborn, Lambert, H. P., Wood, C. B. S., Eds., p. 83 (Academic Press, New York, 1981).

13. Walker, W. A., Wu, M., Isselbacher, K. J., and Bloch, K. J.: Intestinal uptake of macromolecules IV. The effect of pancreatic duct ligation on breakdown of antigen and antigen-antibody complexes on the intestinal surface. Gastroenterology, 69: 1223 (1975).

14. These studies were presented in part at the National Meeting of the Society for Pediatric Research, San Francisco, California, April, 1981.

15. Requests for reprints should be addressed to: Dr. Ronald Kleinman, Pediatric Gastrointestinal and Nutrition Unit, Massachusetts General Hospital, Boston, MA 02114.

16. Dr. Kleinman is supported by the Developmental Biology Training Grant (HDO7092-05).

17. This work was supported by grants from the National Institutes of Health (AM21505, AM-23099, AM-16209, AM-31079-01, HD-12437, GM-21700) and a grant from the HOR Foundation.

18. Received for publication January 8, 1982.

19. Accepted for publication September 17, 1982. 